\title{
AN IN VITRO EVALUATION OF THE LINE PATTERN OF THE NEAR AND FAR WALLS OF CAROTID ARTERIES USING B-MODE ULTRASOUND
}

\author{
Alexander D. Montauban van Swijndregt, ${ }^{\dagger}$ Salem H. K. The, ${ }^{\ddagger *}$ \\ Elma J. Gussenhoven, ${ }^{\ddagger *}$ Charles T. LancÉe, ${ }^{\ddagger}$ Hans Rusterborgh, ${ }^{\ddagger} *$

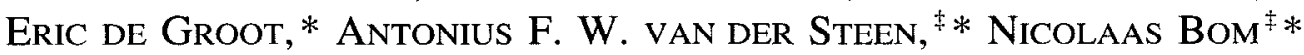 \\ and RoB G. A. ACKERSTAFF ${ }^{\S}$ \\ Department of Radiology, St. Antonius Hospital, Nieuwegein, The Netherlands; ${ }^{\top}$ Thoraxcenter, \\ Erasmus University, Rotterdam, The Netherlands; *Interuniversity Cardiology Institute, Utrecht, \\ The Netherlands; and ${ }^{8}$ Department of Clinical Neurophysiology, St. Antonius Hospital, \\ Nieuwegein. The Netherlands
}

(Received 15 September 1995; in final form 31 May 1996)

\begin{abstract}
This in vitro study was executed to evaluate the double line pattern generated at both near and far walls of human carotid arteries using B-mode ultrasound. Therefore, extravascular (7.5 MHz) and intravascular ( $30 \mathrm{MHz}$ ) ultrasound imaging were performed at the same locations of the carotid artery. The thickness of the double line pattern of the extravascular image (7.5 $\mathrm{MHz}$ ) was compared to the thickness of the intima-media complex seen on the corresponding intravascular image ( $30 \mathrm{MHz}$ ) and on the histologic section. At the far wall of the extravascular image, the measurements were executed at the leading edge of the echo. The data showed high correlation and agreement with the intravascular $(r=0.91, p<0.001$; mean $_{\text {diff }}=-0.01$ and $\left.\mathrm{SD}_{\text {diff }}=0.12\right)$ and the histologic measurements $\left(r=0.87, p<0.001\right.$; mean $_{\text {diff }}=$ -0.12 and $\mathrm{SD}_{\mathrm{dif}}=0.13$ ). In addition, the results of the measurements of the intravascular image showed high correlations and agreement with the histologic data $\left(r_{\text {near }}=0.86, p<0.001 ; \operatorname{mean}_{\mathrm{diff}}=-0.08\right.$ and $\mathrm{SD}_{\text {diff }}=0.15$, respectively, $r_{\mathrm{far}}=0.92, p<0.001 ;$ mean $_{\text {difr }}=-0.12$ and $\mathrm{SD}_{\mathrm{dur}}=0.12$ ). For comparison with other studies, near wall measurements were also included. These had to be performed at the trailing edge of the echoes to be compatible with these studies. The results of the measurements of the extravascular image showed poor correlations and lack of agreement with those of the intravascular $(r=0.49, p=0.03$; mean $_{\text {diff }}=0.09$ and $\left.\mathrm{SD}_{\text {diff }}=0.25\right)$ and of the histologic $\left(r=0.37, p=0.03\right.$; mean ${ }_{\text {diff }}=0.04$ and $\mathrm{SD}_{\text {diff }}=$ 0.23) measurements. These results can easily be explained from the physical limitations of measuring at the trailing edges. We conclude that the double line pattern seen at the far wall of the extravascular image is representative of the intima-media complex. Copyright (C) 1996 World Federation for Ultrasound in Medicine \& Biology
\end{abstract}

Key Words: Arteries, Carotid arteries, Atherosclerosis, Ultrasonography, Ultrasonography, Intravascular, Tunica intima, Tunica media, Ultrasonic tissue characterization.

\section{INTRODUCTION}

Atherosclerosis and subsequent complications such as myocardial infarction, stroke and peripheral vascular disease remain major causes of morbidity and mortality. The process of atherosclerosis is characterized by dynamic progression and repair at an early stage and continuous progression at later periods (Hennerici et al. 1985). The hallmark of atherosclerosis is a thickening of the vascular

Address correspondence to: Dr. Alexander D. Montauban van Swijndregt, St. Antonius Hospital, Koekoekslaan 1, 3435 CM Nieuwegein. The Netherlands. wall due to a pathologic accumulation of lipid within the intima in conjunction with a tissue response (Becker 1989; Ross 1986). Later, the lumen reduces in diameter and clinical symptoms may develop. The process of atherosclerosis has then reached a final stage and is characterized by mineralization, fibrosis, atheronecrosis, ulceration and plaque haemorrhage. Clearly, to establish efficient control of atherosclerosis, lesion stabilization and reversal should begin as early as possible (Blankenhorn and Kramsch 1989).

The presence of atherosclerotic lesions can be evaluated by invasive methods ( such as contrast angi- 
ography ) or noninvasively by ultrasound techniques (Comerota et al. 1984; Ricotta et al. 1987). In contrast to angiography, B-mode ultrasound imaging is able to visualize the vascular wall itself. Pignoli et al. (1984, 1986) were the first to suggest that the double line pattern of the arterial wall, which is seen on the ultrasound B-mode image, represents the lumen-intima and media-adventitia tissue boundaries. The area in between these two lines was, therefore, referred to as the intima-media complex.

If extravascular B-mode ultrasound is to be used as a method in the evaluation of the progression or regression of atherosclerosis by measuring the thickness of the intima-media complex of the vascular wall, these measurements should be performed in a uniform and standardized way. However, controversy still exists on the basic concept of "where and what?" to measure. Pignoli et al. $(1984,1986)$ concluded that only the interfaces of the far wall represented, respectively, the intima-lumen and adventitia-media tissue boundaries. This idea was supported by Picano et al. (1988) and Wendelhag et al. (1991). The latter created a model of the anatomic correlates of the echo interfaces of the arterial wall and concluded that: (1) measurements should always be executed at the leading and not at the trailing edge of the ultrasound echo; and (2) the intima-media thickness of the near wall could not be measured in a valid way due to identification difficulties of the adventitia-media interface. Their in vitro experiments were not validated by histology. In contrast, Mercuri et al. (1991) concluded that the measurements of the intima-media complex at the near wall were valid and reproducible.

Currently, measurements of the intima-media thickness are included in many clinical trials on progression or regression of early atherosclerosis. Some investigators included only measurements at the far wall in thcir studies: for instance, see Salonen et al. (1990), Wendelhag et al. (1992). Veller et al. (1993) and Howard et al. (1994). Othcr investigators included measurements, which were performed at both the near and far wall; for instance, see Bond et al. (1989, 1990), Craven et al. (1990), Handa et al. (1990), O'Leary et al. (1991) and Espeland et al. (1994). To overcome the interpretation problems of adventitia-media interface at the near wall. Espeland et al. (1994) executed measurements at the trailing edge of the ultrasound echo of both the adventitia-media and intima-lumen interface. On the other hand, the measurements at the far wall were executed at the leading edge of the ultrasound echo. A similar strategy was followed by O'Leary et al. ( 1991). In the studies of Veller et al. (1993) and Hodges et al. (1994), the intima-lumen interface of the near wall was included as a reference point. In contrast, Veller et al. (1993) exe- cuted their measurements at the leading edge, while Hodges et al. (1994) executed their measurements at the trailing edge of the ultrasound echo. To entangle the problem even more, Nolsøe et al. (1990) concluded that the line pattern seen at the arterial wall was due $t o$ an artifact generated at plane surfaces of biologic and nonbiologic material using a linear-array transducer. All of the aforementioned studies were transcutaneous investigations, executed with low frequency transducers 15 to 10 $\mathrm{MHz}$ ). Due to this significant disagreement between investigators concerning the validity of the measurements of the intima-media complex at both the near wall and far wall, we conducted the present study.

The aim of this in vitro study was to investigate the double line pattern seen on the extravascular ultrasound image at both the near and far walls of arteries. To this purpose, extravascular $(7.5 \mathrm{MHz})$ and intravascular $(30 \mathrm{MHz})$ ultrasound imaging were performed at the same locations of the carotid artery. The thickness of the double line pattern of the extravascular image was compared to the thickness of the intimamedia complex of the intravascular image and of the histologic sections.

\section{METHODS}

\section{Specimen}

In total, ten carotid arteries were excised at autopsy from eight patients aged 24 to 71 years (mean 42 years) who had no history of stroke or cerebral vascular disease. Immediately, subcutaneous tissue and nearly the complete periadventitia was removed, and only a small rim remained. Care was taken not to damage the adventitia. The artcries were frozen and stored at $-20^{\circ} \mathrm{C}$. To execute the study, the arteries were defrosted at room temperature.

The external carotid artery and its branches were ligated and the cut edges of the common carotid and internal carotid arteries were cannulated. The artery was embedded in a bath filled with purified water and kept at room temperature, approximately $1 \mathrm{~cm}$ below the water surface. To preserve the geometry of the artery, the cannulas were attached to a water column corresponding to a pressure of $80 \mathrm{mmHg}$. During ultrasonic imaging, the pressure in the lumen of the artery was maintained and controlled by a syringomanometer.

\section{Extravascular ultrasound system}

The imaging was performed with a color Doppler B-mode ultrasound system (Acuson 128, Mountain View, CA, USA) with a linear-array $7.5-\mathrm{MHz}$ transducer (L7384). The aperture of the transducer, containing 128 elements, is $38 \mathrm{~mm}$ in length. For transmit foci within a range of $35 \mathrm{~mm}$, the measured pulse length at $-6 \mathrm{~dB}$ is $0.5 \mu \mathrm{s}$, corresponding to an axial 
resolution of approximately $0.4 \mathrm{~mm}$ for an ultrasonic speed of $1540 \mathrm{~m} / \mathrm{s}$. By using the regional expansion solution (RES) mode improved visualization of a localized area of interest could be provided. At a depth range of $35 \mathrm{~mm}$, the RES mode will not affect the axial resolution.

\section{Intravascular ultrasound system}

The imaging was performed with a $30-\mathrm{MHz}$ single-element transducer (Du-MED, Rotterdam, The Netherlands) mounted on a $5 \mathrm{~F}$ catheter tip. The system was based on a mechanically motor-driven rotating catheter tip element connected to a flexible shaft, which provided continuous real-time cross-sections of the vessel wall (up to 16 images per second). The element was covered by an acoustically transparent dome. The axial resolution of the system was $0.075 \mathrm{~mm}$. The ultrasound studies were carried out by placing the catheter in the lumen of the artery.

\section{Ultrasound procedure}

The extravascular transducer was placed in a holder and posilioned perpendicular to the artery. At the same time, the intravascular transducer was introduced through the plastic cannula at the site of the common carotid artery. At first, the extravascular procedure was executed. The longitudinal images of the near and far wall were optimized separately and the image was adjusted by using time gain control (TGC). Afterwards, the intravascular procedure was executed. The transversal images of the corresponding locations were optimized separately and recorded in the largest magnification possible (Fig. 1). Each site of interest was marked using a reference needle placed through the periadventitia of the near wall. At subsequent intervals, a total of 47 images were acquired (34 images of the common and 13 images of the internal carotid arteries). All extravascular and intravascular ultrasound images were recorded with a video recorder (Panasonic NV-FS100 HQ).

\section{Histologic preparations}

For histologic comparison, the arteries were fixed for $60 \mathrm{~min}$ in a $10 \%$ buffered formalin solution maintaining the intraluminal pressure at $80 \mathrm{mmHg}$. Subsequently, the vessels were stored in a $10 \%$ buffered formalin solution for at least $24 \mathrm{~h}$ before histologic preparation was performed. The arteries were processed for routine paraffin embedding. Transverse sections ( $5 \mu \mathrm{m}$ thick) were cut perpendicular to the longitudinal axis of the artery at the site of the reference needle. The sections were stained with Verhoeff's elastin van Gicson stain technique.

\section{Measurements}

The video frames of the extravascular and intravascular images were digitized to measure the wall thickness (Sony GVM-1400 QM Triniton Color Videomonitor, Panasonic NV-FS100 HQ Videorecorder, Digital Time Base Corrector IVT-7P).

Extravascular images. The thickness of the near wall was defined as the distance between the trailing edges of the first and second echoes; whereas the thick-

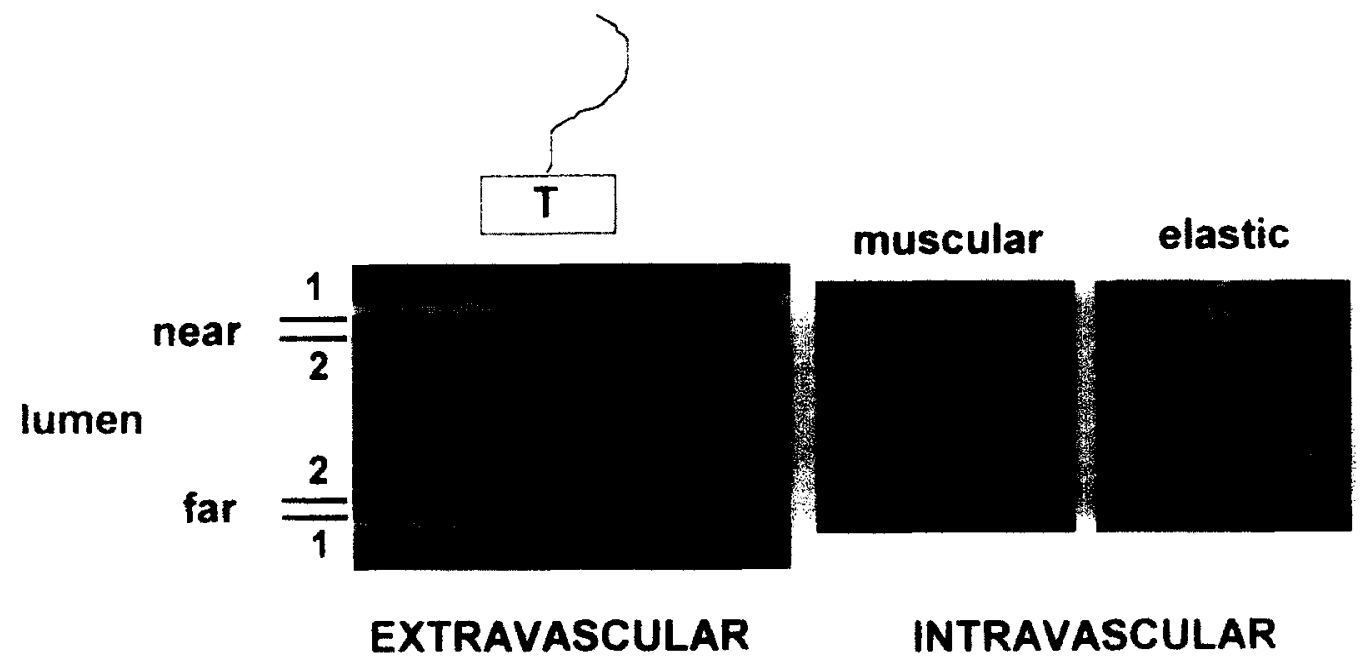

Fig. 1. Showing the longitudinal image of the extravascular ultrasound ( $7.5 \mathrm{MH}$ ) and the transverse images of the intravascular ultrasound $(30 \mathrm{MHz}$ ) procedures obtained from the internal carotid (muscular) and common carotid (elastic) artery. The thickness of the arterial wall is defined as the distance between the two hyperechoic interfaces (double line pattern) of the extravascular image (see 1 and 2 ). 
Table 1. The thickness (millimeters) of near and far walls in carotid arteries.

\begin{tabular}{|c|c|c|c|}
\hline Lociation & No. & Mean $\perp S D$ & Range \\
\hline \multicolumn{4}{|l|}{ Near wall } \\
\hline Extra & 39 & $0.74 \pm 0.18$ & $0.40-1.11$ \\
\hline Intra & 40 & $0.81 \pm 0.31$ & $0.27-1.49$ \\
\hline Histo & 43 & $0.75 \pm 0.25$ & $0.27-1.21$ \\
\hline \multicolumn{4}{|l|}{ Far wall } \\
\hline Extra & 46 & $0.86 \pm 0.25$ & $0.27-1.49$ \\
\hline Intra & 45 & $0.84 \pm 0.28$ & $0.30-1.39$ \\
\hline Histo & 44 & $0.74 \pm 0.24$ & $0.32-1.20$ \\
\hline
\end{tabular}

$\mathrm{SD}=$ standard deviation; Extra $=$ extravascular image; Intra $=$ intravascular image: Histo $=$ histologic sections.

ness of the far wall was defined as the distance between the leading edges of the first and second echo (Figs. 1 and 4).

Intravascular images. At the corresponding locations, measurements of the intima-media thickness were executed from the luminal boundary to the boundary of the adventitia.

Histology. Measurements from the histologic sections were executed from endothelium to adventitia at the corresponding locations, using a computerized technique (Kontron Bildanalyse, IBAS 2000 system, München, Germany).

Measurements were executed by manually tracking the defined distance with an interactive cursor.

\section{Statistical analysis}

The statistical significance of the difference between the results of the measurements of the extravascular and intravascular ultrasound procedures and histology were evaluated using linear regression analysis. The regression equation was separately calculated for near and far walls and was plotted in a scatter diagram. According to the method described by Bland and Altman (1986) for the assessment of the agreement between methods, the differences of the corresponding measurements were plotted against the mean of the measurements.

\section{RESULTS}

\section{Ultrasound and histology}

Extravascular ultrasound of both the common and internal carotid arteries revealed a double line pattern in all 47 acquired images (Fig. 1). The double line pattern was characterized by a relative hypoechoic zone located between two hyperechoic interfaces and was seen at both the near and far wall. In contrast, this double line pattern was not shown in the intravascular ultrasound images. The intima-media complex of the common carotid artery was seen as a homogeneous echo-bright structure due to the elastic fibers present in the media. Conversely, the intima-media complex of the internal carotid artery showed a relative hypoechoic zone, due to the muscular fibers in the media (Fig. 1).

\section{Near wall measurements}

A total of 39 extravascular, 40 intravascular and 43 histologic thickness measurements were included for evaluation (Table 1). We excluded eight extravascular and seven intravascular images for quantitative measurements, given the poor quality of the images. Additionally, four histologic cross-sections were excluded due to damage of the specimen at the site of the near wall. The correlation coefficient calculated between the matched results of the thickness of (1) extravascular. (2) intravascular and (3) histologic measurements are shown in Table 2 . A high correlation was found between the results of the intravascular and histologic measurements $(r=0.86, p<0.001)$ (Table 2, Fig. 2). The results of the extravascular measurements showed a poor correlation with both intravascular $(r=0.49, p=0.03)$ and histologic $(r=0.37$. $p=0.03$ ) examinations (Table 2. Fig. 2). For the extravascular procedure, a lack of agreement was observed with both intravascular ( mean $_{\text {diff }}=0.09$. $\mathrm{SD}_{\text {diff }}$ $=0.25)$ and histologic $\left(\operatorname{mean}_{\text {diff }}=0.04, \mathrm{SD}_{\text {diff }}=0.23\right)$ findings (Table 3, Fig. 2). On the other hand, good agreement between methods was obtained between the intravascular and histologic procedures $\left(\right.$ mean $_{\text {diff }}=$ $-0.08, \mathrm{SD}_{\text {diff }}=0.15$ ).

\section{Far wall measurements}

A total of 46 extravascular, 45 intravascular and 44 histologic thickness measurements were included

Table 2. Comparison of extravascular, intravascular and histologic measurements.

\begin{tabular}{cccccc}
\hline & \multicolumn{2}{c}{ Near wall } & & \multicolumn{2}{c}{ Far wall } \\
\cline { 5 - 6 } & Extra & Intra & & Extra & Intra \\
\hline Histo & & & & \\
No. & 35 & 36 & & 43 & 42 \\
$r$ & 0.37 & 0.86 & & 0.87 & 0.92 \\
$p$ & 0.03 & $<0.001$ & $<0.001$ & $<0.001$ \\
Intra & & & & 44 & \\
No. & 34 & & 0.91 & \\
$r$ & 0.49 & & $<0.001$ & \\
$p$ & 0.03 & & &
\end{tabular}

No. $=$ number of measurements available after comparison; $r=$ correlation coefficient; $p=p$-value; Extra = extravascular ultrasound image; Intra $=$ intravascular ultrasound image; Histo $=$ histologic sections. 

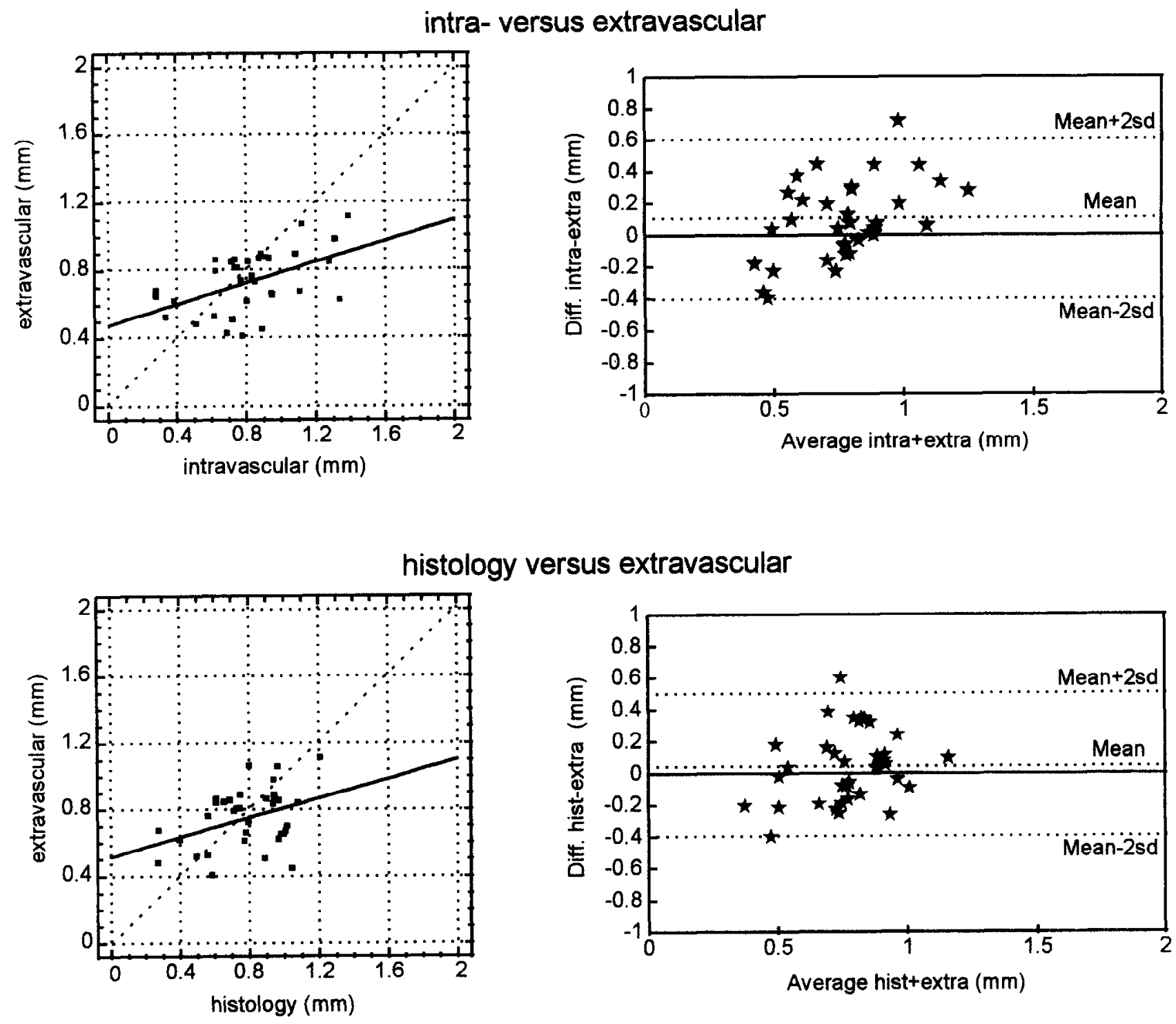

\section{histology versus intravascular}
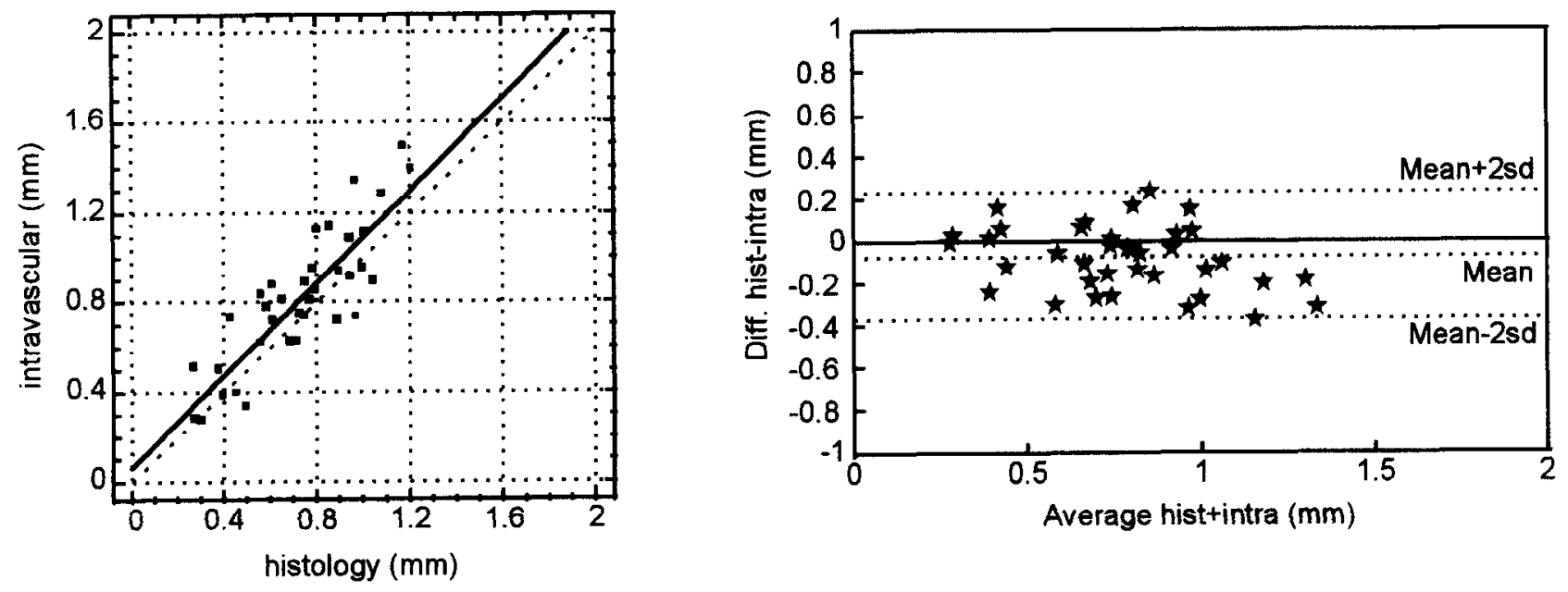

Fig. 2. Comparison between the extravascular, intravascular and histologic measurements of intima-media thickness of the near wall. Left: measurements $(\mathrm{mm})$ according to the linear regression analyses and lines of identity. Right: differences versus means of measurements acquired by the three different methods. 
intra- versus extravascular
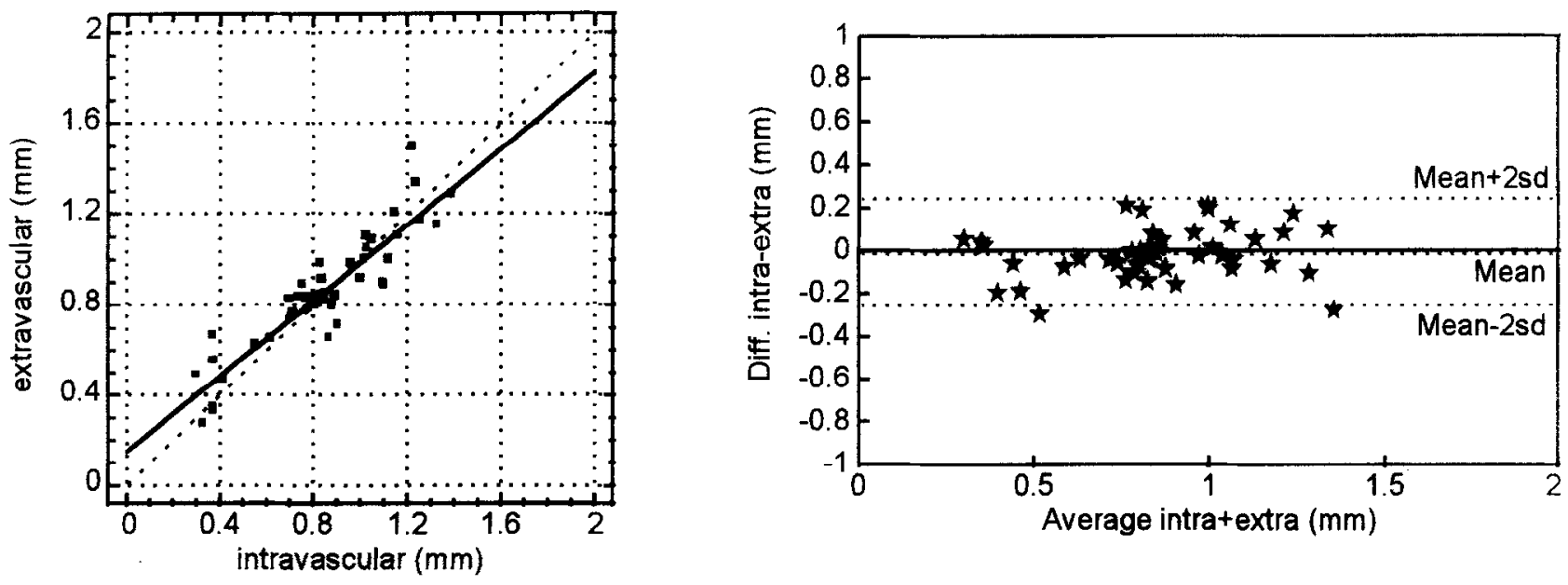

histology versus extravascular
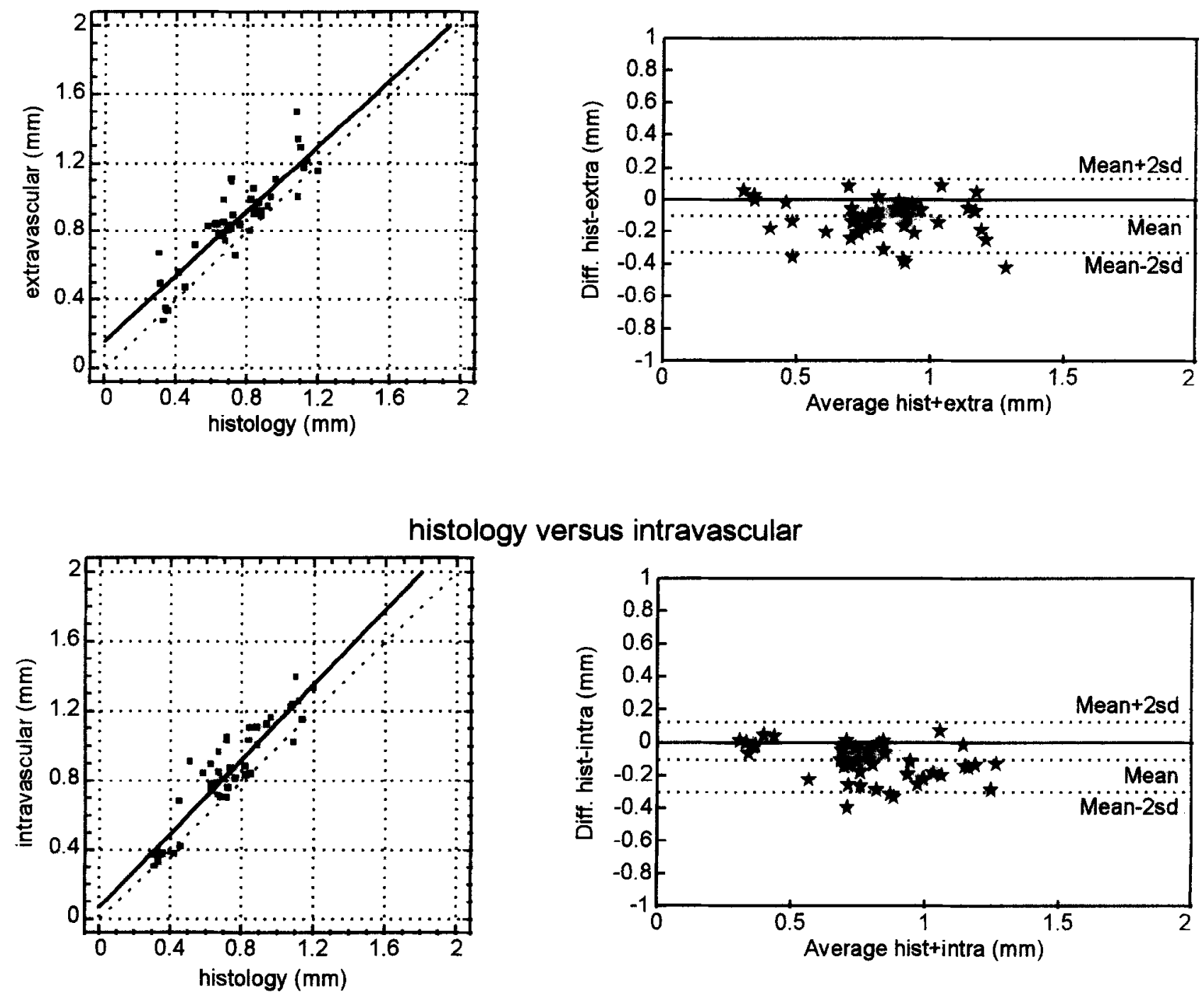

Fig. 3. Comparison between the extravascular, intravascular and histologic measurements of intima-media thickness of the far wall. Left: measurements $(\mathrm{mm})$ according to the linear regression analyses and lines of identity.

Right: differences versus means of measurements acquired by the two methods. 


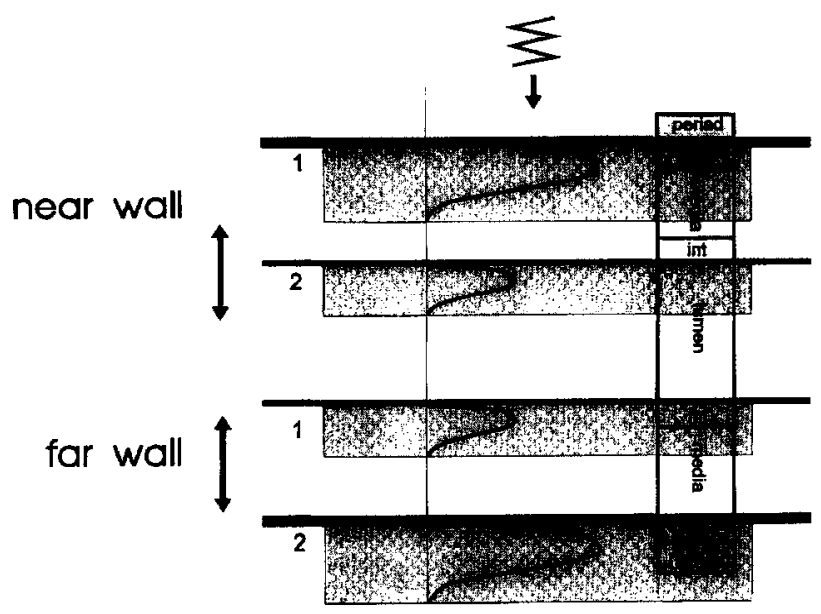

Fig. 4. The interfaces $(1$ and 2 ) being generated at changes of acoustic impedance between two substances seen at a frequency of $7.5 \mathrm{MIIz}$. At the near wall, mcasurcments are executed at the trailing edge of the echo. At the far wall, measurements are executed at the leading edge of the echo.

for evaluation (Table 1). The exclusion of one extravascular and two intravascular ultrasound images was due to interpretation problems. The three histologic sections were excluded due to damage to the specimen at the site of the far wall. The correlation coefficients calculated between the matched results of the thickness of (1) extravascular, (2) intravascular and (3) histologic measurements are shown in Table 2. We found high correlation between the results of the extravascular measurements and both the intravascular $(r=0.91$, $p<0.001)$ and histologic $(r=0.87, p<0.001)$ measurements. A high correlation was also observed between the results of the intravascular and histologic measurements ( $r=0.92, p<0.001$ ) (Tablc 2, Fig. 3). Also, good agreement was shown between all methods used (Table 3, Fig. 3 ).

\section{DISCUSSION}

In the present in vitro study, the line pattern as seen at the near and far wall of the extravascular ultrasound images was investigated. In all cases of the extravascular ultrasound procedure, a double line pattern was shown at both the near and far wall (Fig. 1). The distance between these two lines was compared with the thickness of the intima-media complex as measured on the intravascular ultrasound images and on the histologic sections (Table 2, Fig. 4). Due to the study design, we were able to: (1) maintain the normal geometry of the artery; (2) evaluate the effect of the direction of the ultrasound wave using extravascular and intravascular transducers; and (3) assess unfixed tissue during extravascular and intravascular ultrasound imaging, since a shrinkage of tissue was documented during the process of fixation (Wong et al 1993). The histologic part of the study (fixed tissue) was included because this is considered as the gold standard. As demonstrated in Table 2, at the near $(r=0.86$, $p<0.001)$ and far wall $(r=0.92, p<0.001)$, a high correlation was found between the intravascular and histologic measurements. In Table 3, the agreement between methods is shown (Bland and Altman 1986). At the far wall, the standard deviation of the differences between the extravascular $\left(\right.$ mean $_{\text {diff }}=-0.12, \mathrm{SD}_{\text {diff }}=$ $0.13)$, and intravascular $\left(\operatorname{mean}_{\text {diff }}=-0.12, \mathrm{SD}_{\text {diff }}=\right.$ 0.12 ) examination and the histologic examination are of the same order. In all likelihood, the resolution of the intravascular ultrasound system is not the limiting factor in the process of data acquisition.

The usefulness of ultrasound as an imaging tool is primarily the result of reflection and scattering at tissue boundaries and scattering within heterogeneous tissues. It is suggested that collagen and elastin fibers are dominant factors in the echographic visibility of arteries (Geleski and Shung 1982; Gussenhoven et al. 1989; Lockwood et al. 1992; Picano et al. 1988; Rooney et al. 1982). Based on the anatomy of the vascular wall, several tissue boundaries can be defined. At the near wall, we recognize: (1) the periadventitaadventitia; (2) the adventitia-media; ( 3 ) the mediaintima; and (4) the intima-lumen boundary. At the far wall, the tissue boundaries have a reversed notation: (1) lumen-intima; (2) intima-media; (3) media-adventitia; and (4) adventitia-periadventitia boundary (Fig. 4). The ultrasound wave will reflect on these tissue boundaries, depending on the difference in acoustic impedance between tissues (Kremkau 1989). We observed, in all extravascular examinations, a double line pattern in both muscular and elastic arteries. The echoes originating at the media-intima or intimamedia boundary could not be resolved, due to the lim-

Table 3. Agreement between extravascular, intravascular and histologic measurements.

\begin{tabular}{lccccc}
\hline & \multicolumn{2}{c}{ Near wall } & & \multicolumn{2}{c}{ Far wall } \\
\cline { 2 - 3 } & Extra & Intra & & Extra & Intra \\
\hline Histo & & & & \\
No. & 35 & 36 & & 43 & 42 \\
Mean $_{\text {diff }}$ & 0.04 & -0.08 & -0.12 & -0.12 \\
SD $_{\text {ditf }}$ & 0.23 & 0.15 & & 0.13 & 0.12 \\
Intra & & & & \\
No. & 34 & & & 44 & \\
Mean $_{\text {diff }}$ & 0.09 & & -0.01 & \\
SD dift & 0.25 & & 0.12 & \\
\hline
\end{tabular}

No. $=$ number of measurements; mean $_{\text {diff }}=$ mean of the differences (method $1-$ method 2 ) in millimeters; $\mathrm{SD}_{\text {diff }}=$ standard deviation of the differences; Extra = extravascular ultrasound image; Intra $=$ intravascular ultrasound image: Histo $=$ histologic sections. 
ited resolution of the ultrasound system (Fig. 4) ( Nolsøe et al. 1990; Wendelhag et al. 1991).

In the present study, for the extravascular procedures, a discrepancy was noticed between the results of the near and far wall measurements. The high correlations of the far wall measurements with both the intravascular $(r=0.91, p<0.001)$ and histologic $(r$ $=0.87 . p<0.001$ ) findings, combined with the good agreement between methods according to the method of Bland and Altman (1986), were not observed for the near wall measurements $(r=0.49$ and $r=0.37$; $p=0.03$ ) (Tables 2 and 3 and Figs, 2 and 3). At the near wall, to be compatible with the many in vivo studies, the trailing edges of the echoes from the adventitia-media and the intima-lumen interface were measured (Fig. 4). Measurements at the leading edge were not performed in these in vivo studies because of interpretation problems of the first interface (Espeland et al. 1994). As shown in Fig. 5, at a certain threshold level, the echo will become visible. At the leading edge, a small reading error might be introduced, which is a negligible factor at the varying gain settings or reflectivity of the interfaces. Conversely. a significant reading error will be introduced at the trailing edge by gain settings and reflectivity of the interfaces. Therefore, at the near wall of the extravascular ultrasound image, the intima-media complex cannot be correctly visualized, which resulted in the observed poor correlations and lack of agreement. At the far wall of the extravascular ultrasound image, the pathway of ultrasound is reversed. The beam of sound travels from intima to periadventitia. At the lumen-intima interface (Figs. 1 and 4, no. 2) the trailing portion of the ultrasound echo will project into the intima-media complex, whereas, at the media-adventitia interface (Figs. 1 and 4, no. 1), the trailing portion of the echo will project into the periadventitia and will not interfere with the measurements. Also, these measurements are hardly influenced by gain settings (Fig. 5). This resulted in the observed high correlations and agreement between methods. We emphasize that measurements should, for that reason, always be executed at the leading edge of the echo. In contrast to the near wall. we consider the area at the far wall between the two

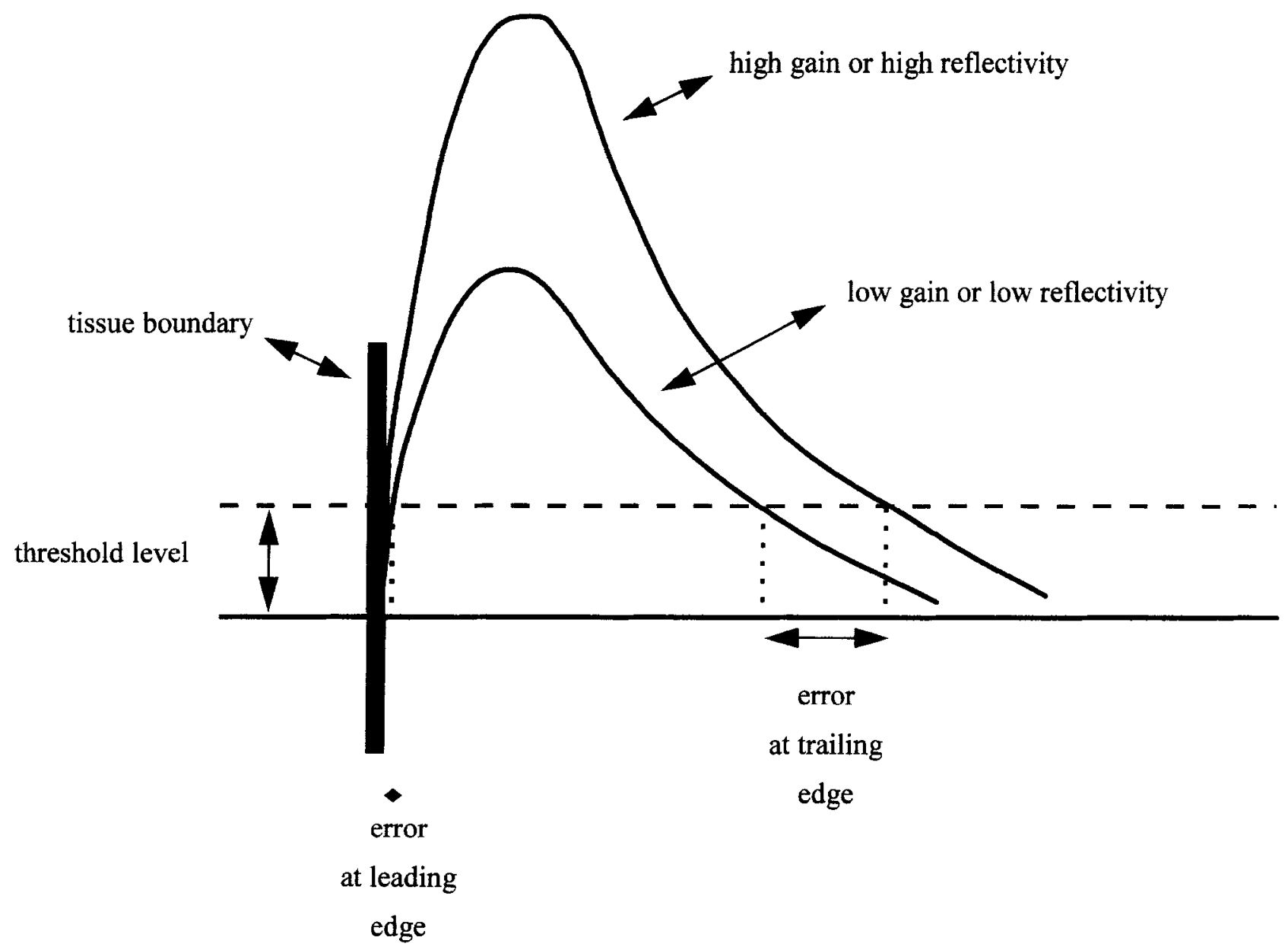

Fig. 5. Influence of gain settings or reflectivity on estimating leading and trailing edges of ultrasound echoes. 
interfaces to be representative of the intima-media complex. During intravascular ultrasound imaging, the transducer is situated within the lumen of the artery (Fig. 1). At all locations, the pathway of ultrasound is then comparable to the far wall of the extravascular ultrasound procedure (intima to adventitia). This resulted in the high correlations and agreement between the data of the intravascular and histologic measurements at both the near and far wall (Tables 2 and 3 ).

In summary, at a frequency of $7.5 \mathrm{MHz}$, in all cases, the image of the vascular wall was represented by a double line pattern. With regard to this double line pattern, an important difference was noticed between the results of the near and far wall measurements. At the far wall, we found high correlations between the results of the extravascular, intravascular and histologic measurements and good agreement between methods. On the contrary, at the near wall, the double line pattern of the extravascular image did not correlate with the thickness of the intima-media complex of the intravascular image and with the histologic sections. In addition, a lack of agreement between methods was found.

We conclude that only the double line pattern seen at the far wall is representative of the intima-media complex and can be included in clinical intervention trials which use the thickness of the intima-media complex as a parameter in the regression or progression of atherosclerosis.

Acknowledgements-We thank Dr. R. J. van Suylen, who most kindly gave us the opportunity to use the "Kontron Bildanalyse. IBAS 2000" system (Medical Faculty, Erasmus University Rotterdam, Department of Pathology) and Mr. B. S. Primack for reading the manuscript.

\section{REFERENCES}

Becker AE. Ultrasound imaging and atherogenesis. Int J Card Imag 1989;4:99-104.

Bland JM, Altman DG. Statistical methods for assessing agreement between two methods of clinical measurement. Lancet 1986; 8:307-310.

Blankenhorn DH, Kramsch DM. Reversal of atherosis and sclerosis. The two components of atherosclerosis. Circulation 1989;79:1-7.

Bond MG, Strickland HL, Wilmoth SK, Safrit A, Phillips R. Interventional clinical trials using noninvasive ultrasound end points: the Multicenter Isradipine/Diuretic Atherosclerosis Study. The MIDAS Research Group. J Cardiovasc Pharmacol 1990; 15 (suppl 1):30-33.

Bond MG, Wilmoth SK, Enevold GL, Strickland HL. Detection and monitoring of asymptomatic atherosclerosis in clinical trials. Am J Med 1989;86:33-36.

Comerota AJ, Cranley JJ, Katz ML, Cook SE, Sippel PJ. Real-time B-mode carotid imaging. A three-year multicenter experience. J Vasc Surg 1984:1:84-95.

Craven TE, Ryu JE. Espeland MA, Kahl FR, McKinney WM. Evaluation of the associations between carotid artery atherosclerosis and coronary artery stenosis. A case-control study. Circulation $1990 ; 82: 1230-1242$.

Espeland MA, Hoen H, Byington R. Howard G, Riley WA. Spatial distribution of carotid intimal-medial thickness as measured by B-mode ultrasonography. Stroke 1994;25:1812-1819

Geleski JV, Shung KK. Further studies on acoustic impedance of major bovine blood vessel walls. J Acoust Soc Am 1982: 71:467470.

Gussenhoven EJ, Essed CE, Lancée CT, Mastik F. Frietman P. Arterial wall characteristics determined by intravascular ultrasound imaging: an in vitro study. J Am Coll Cardiol 1989; 14:947-952.

Handa N, Matsumoto M, Maeda H, Hougaku H, Ogawa S. Ultrasonic evaluation of early carotid atherosclerosis. Stroke 1990: $21: 1567-1572$.

Hennerici M, Rautenberg W, Trockel U, Kladetzky RG. Spontaneous progression and regression of small carotid atheroma. Lancet $1985 ; \mathrm{i}: 1415-1419$.

Hodges TC, Detmer PR, Dawson DL, Bergelin RO, Beach KW. Ultrasound determination of total arterial wall thickness. J Vasc Surg 1994: 19:745-753.

Howard G, Burke GL. Evans GW. Crouse JR, Riley W. for the ARIC investigators. Relations of intimal-medial thickness among sites within the carotid artery as evaluated by B-mode ultrasound. Stroke 1994;25:1581-1587.

Kremkau FW. Diagnostic ultrasound: principles; instruments and exercises, 3rd ed. Philadelphia: Saunders 1989:41-5I.

Lockwood GR, Ryan LK, Gotlieb AI, Lonn E, Hunt JW. In vitro high resolution intravascular imaging in muscular and elastic arteries. J Am Coll Cardiol 1992:20:153-160.

Nolsøe CP, Engel U, Karstrup S, Torp-Pedersen S, Garre K. The aortic wall: an in vitro study of the double-line pattern in highresolution US. Radiology 1990; 175:387-390.

O'I eary DH, Polak JF, Wolson SK, Bond MG, Bommer WA. Use of sonography to evaluate carotid atherosclerosis in the elderly. The cardiovascular health study. Stroke $1991 ; 22: 1155-1163$.

Picano E, Landini L, Lattanzi F, Salvadori M, Benassi A. Time domain echo pattern evaluations from normal and atherosclerotic arterial walls: a study in vitro. Circulation 1988;77:654-659.

Pignoli P. Ultrasound B-mode imaging for arterial wall thickness measurement. Atheroscler Rev 1984: 12:177-183.

Pignoli P, Tremoli E, Poli A, Oreste P, Paoletti R. Intimal plus medial thickness of the arterial wall: a direct measurement with ultrasound imaging. Circulation 1986; 74:1399-1406.

Ricotta JJ, Bryan FA, Bond MG, Kurtz A, O'Leary DH. Multicenter validation study of real-time (B-mode) ultrasound; arteriography; and pathologic examination. J Vasc Surg 1987;6:512-520.

Rooney JA. Gammell PM, Ilestenes JD. Chin IIP. Blankenhorn DH. Velocity and attenuation of sound in arterial tissues. J Acoust Soc Am 1982:71:462-466.

Ross R. The pathogenesis of atherosclerosis - an update. N Engl J Med 1986;314:488-500.

Salonen R, Salonen JT. Progression of carotid atherosclerosis and its determinants: a population-based ultrasonography study. Atherosclerosis 1990;81:33-40.

Veller MG, Fisher CM, Nicolaides AN, Renton S. Geruulakos G. Measurement of the ultrasonic intima-media complex thickness in normal subjects. J Vasc Surg 1993: 17:719-725.

Wendelhag I, Gustavsson T. Suurküla MJ, Berglund G. Wikstrand Ultrasound measurement of wall thickness in the carotid artery: fundamental principles and description of a computerized analysing system. Clin Physiol 1991;1 1:565-577.

Wendelhag I. Wiklund O, Wikstrand J. Arterial wall thickness in familial hypercholesterolemia. Ultrasound measurement of intima-media thickness in the common carotid artery. Arterioscler Thromb 1992; 12:70-77.

Wong M, Edelstein J. Wollmann I, Bond MG. Ultrasonic--pathological comparison of the human arterial wall. Verification of intima-media thickness. Arterioscler Thromb 1993;13:482-486. 